\title{
Biosensors and Bioremediation as Biotechnological Tools for Environmental Monitoring and Protection
}

\author{
Haleema Bano ${ }^{1}$, Shayesta Islam ${ }^{1}$, Faisal Noor ${ }^{2}$ and M. Ashraf Bhat ${ }^{3^{*}}$ \\ ${ }^{1}$ Division of Environmental Sciences, ${ }^{2}$ Division of Vegetable Science, ${ }^{3}$ Division of Genetics \\ and Plant Breeding, Sher-e-Kashmir University of Agricultural Sciences and Technology of \\ Kashmir, Shalimar- 190 025, Srinagar, Jammu and Kashmir, India \\ *Corresponding author
}

\section{A B S T R A C T}

\section{Keywords}

Biosensor, Phytoremediation, Phytostabilization, Enzymes, Optical Biosensors, Microorganisms, Antibodies

Article Info

Accepted: 26 September 2020 Available Online: 10 October 2020
Environmental biotechnology is the integration of natural sciences and engineering in order to achieve the application of organisms, cells, parts thereof and molecular analogues for the protection and restoration of the quality of our environment. Biotechnological processes to protect the environment have been used for almost a century now, even longer than the term "biotechnology" exists. Biotechnological techniques to treat waste before or after it has been brought into the environment are components of environmental biotechnological tools. Biotechnology can also be applied industrially for use in developing products and processes that generate less waste and use less nonrenewable resources and consume less energy. A biosensor is an analytical device that integrates a biological sensing element (e.g., an enzyme or an antibody) with a physical (e.g., optical, mass, or electrochemical) transducer, whereby the interaction between the target and the bio-recognition molecules is translated into a measurable electrical signal. Potent alternatives to conventional analytical techniques are Optical biosensors that exploit light absorption, fluorescence, luminescence, reflectance, Raman scattering and refractive index. Devoid of any time-consuming sample concentration and or prior sample pretreatment steps these biosensors provide rapid, highly sensitive, real-time, and highfrequency monitoring. Although optical biosensors have great potential applications in the areas of environmental monitoring, food safety, drug development, biomedical research, and diagnosis. Their use in fields of environmental pollution control and early warning is still in the early stages. Biosensors are classified according to their transduction principle such as optical, electrochemical and piezoelectric or based on their recognition element as immunosensors, apt sensors, genosensors, and enzymatic biosensors, when antibodies, aptamers, nucleic acids, and enzymes are, respectively, used.

\section{Introduction}

Biotechnology is the use of living organisms such as bacteria or plants or other unicellular or simple multi-cellular organisms. To make it more practical and suitable for our product genetically modified strains as well as desired strains to get desired products can be chosen. The entire biological system has been being affected due to human activities which have 
polluted the environment with harmful and poisonous contaminants from past few decades. As a result ecological balance is severely disturbed (Khalilian et al., 2015). Conventional goods are manufacture by manipulating the hereditary bases of living organisms using biotechnological tools. (Chen et al., 2005) clearly elaborated that environmental attractiveness is progressed through the use of micro-organisms (Chen et al., 2005). With the advent of advance technologies from molecular and microbial biology has enabled researchers to solve environmental problems e.g. degradation/detoxification of waste by the use of living organisms (Bharagava et al., 2020). Bioremediation is branch of biotechnology which can remove pollutants and hazardous material from water and soil through microorganisms and also protects ecosystem. The easily disposed simple forms of compounds into natural environment or used as manure for soil improvement are the conversion products of complex organic compounds using anaerobic microbe based process called composting.

Technologies involving the use of genetically modified organisms microorganisms or plants; they could also involve different strains of yeast. Insects and mammalian cell lines could be useful too. The most outstandingly used are bacteria and its different strains. Because these can be grown in large quantities and their genome study is not a tough job. These can be easily modified. These techniques include Landfill, Biosensors, Bioremediation, Compositing, Oil eating bugs, Biodegradation of xenobiotic, Bio mining, Designer bugs, Pollution control, Treating industrial waste, Bio scrubbing, Pest control and bio pesticides, Weed control, Restoration of denuded areas, Viral pesticides, Bio fertilizers, Bio diversity and conservation technologies etc.

\section{Environmental biotechnology}

Environmental biotechnology is the integration of natural sciences and engineering in order to achieve the application of organisms, cells, parts thereof and molecular analogues for the protection and restoration of the quality of our environment. Biotechnological processes to protect the environment have been used for almost a century now, even longer than the term "biotechnology" exists. About the turn of the century for purification of town gas Municipal sewage treatment plants and filters were developed. Even though, little was wellknown about the biological principles underlying their function at that time, still they proved effective. Since that time, our knowledge base has amplified extremely. Biotechnological techniques to treat waste before or after it has been brought into the environment are components of environmental biotechnological tools. Biotechnology can also be applied industrially for use in developing products and processes that generate less waste and use less nonrenewable resources and consume less energy. In this respect biotechnology is well positioned to contribute to the development of a more sustainable society through a sustainable environment. Recombinant DNA technology has improved the possibilities for the prevention of pollution and holds a promise for a further development of bioremediation. What this means for environmental biotechnology is that it is futuristic and limitless in application and usage. (European Federation of Biotechnology 1999).

\section{Biosensors}

A biosensor is an analytical device that integrates a biological sensing element (e.g., an enzyme or an antibody) with a physical (e.g., optical, mass, or electrochemical) 
transducer, whereby the interaction between the target and the bio-recognition molecules is translated into a measurable electrical signal (Thevenot et al., 2001). Potent alternatives to conventional analytical techniques are Optical biosensors that exploit light absorption, fluorescence, luminescence, reflectance, Raman scattering and refractive index. Devoid of any time-consuming sample concentration and/or prior sample pretreatment steps these biosensors provide rapid, highly sensitive, real-time, and highfrequency monitoring. Although optical biosensors have great potential applications in the areas of environmental monitoring, food safety, drug development, biomedical research, and diagnosis (Borisov et al., 2008, Shankaran et al., 2007) their use in fields of environmental pollution control and early warning is still in the early stages.

Biosensors can be classified according to their transduction principle such as optical (including optical fibre and surface plasmon resonance biosensors), electrochemical (including amperometric, and impedance biosensors), and piezoelectric (including quartz crystal microbalance biosensors) or based on their recognition element as immunosensors, apt sensors, genosensors, and enzymatic biosensors, when antibodies, aptamers, nucleic acids, and enzymes are, respectively, used.

In environmental monitoring, the majority of biosensors are identified as immunosensors and enzymatic biosensors, but recently the development of apt sensors has been increased, due to the advantageous characteristics of aptamers such as easiness to modify, thermal stability, in-vitro synthesis, and possibility to design their structure, to distinguish targets with different functional groups, and tore hybridize (Justino et al., 2015).

\section{Biosensors on the basis of recognition elements}

Enzymes: These are biological molecules that catalyze specific chemical reactions because of specificity for substrate. One of the tremendously important properties of enzymes is immobilization on solid substrate, because the immobilization method can enhance the working lifetime and sensitivity of the biosensors. The optical transducers of enzymebased biosensors are at the heart of the development of compact, self-contained devices for environmental monitoring. ChE biosensors are of fastidious interest in the area of universal toxicity monitoring because Cholinesterase (ChE) enzymes can be inhibited by several toxic chemicals such as organophosphates and pesticides, heavy metals, and toxins. (Borisov et al., 2008, Ispas et al., 2012, Luckham et al., 2010]. Considering that different pollutants inhibit enzyme activity in various ways, multianalyte detection can be achieved using enzyme sensors. For example, pesticides and heavy metal ions can be detected simultaneously in a sample solution through the inhibition of butyrylcholine esterase by pesticides and urease by heavy metals ions (Borisov et al., 2008, Ligler et al., 2009, Malitest et al., 2005). Toluene ortho-monooxygenase is used as biorecognition constituent, and an oxygenresponsive ruthenium-based phosphorescent dye serve as transducer for the measurement of Toluene in aqueous solution in enzymatic biosensor (Zhongn et al., 2011). The phosphorescence intensity of the oxygenreceptive probe is changed due to the enzyme catalyzed expenditure of Oxygen which helps in the determination of Toluene. Although the enzymatic biosensor can detect toluene in wastewater with a limit of detection (LOD) of 3 $\mu \mathrm{M}$ and a linear signal range up to $100 \mu \mathrm{M}$, the response time is long $(1 \mathrm{~h})$, and the activity decreases with each measurement and with storage time. 
Antibodies: Antibodies against haptens, such as pesticides, persistent organic pollutants (POPs), and endocrine disrupting chemicals (EDCs), are prepared by synthesizing immunogens from the covalent binding of the hapten to a carrier protein and then immunizing them into animals. The creation of the chemical binding of the hapten to the carrier protein, called complete antigen determines the specificity and quality of antibody which is important for immunoassay (Dorst et al., 2010). The most frequent and most toxic hepatotoxin, microcystin-LR (MC$\mathrm{LR}$ ), is detected by complete antigen (MCLR-BSA) which is synthesized by introducing a primary amino group in the seventh $\mathrm{N}$ methyl dehydro alanine residue of MC-LR. The product amino ethyl-MC-LR was then coupled to bovine serum albumin (BSA) with glutaraldehyde. A monoclonal antibody (Clone MC8C10) against MC-LR was produced by immunization with MC-LRBSA. MCs in waters are detected due to the establishment of indirect competitive enzymelinked immunosorbent assay (ic-ELISA) with MC8C10, which show high specificity with a detection bound of $0.1 \mu \mathrm{g} / \mathrm{L}$ for MC-LR (Sheng et al., 2007).Aptamers: An aptamer, a single-stranded DNA or RNA sequence composed of about 50-80 nucleotides selected by Systematic Evolution of Ligands by Exponential enrichment (SELEX), binding of aptamer to its target is very selective, through folding into a complex three-dimensional structure (Borisov et al., 2008, Ligler et al., 2009, Dorst et al., 2010, Ellington et al., 1990, Turek et al., 990). The interaction between the aptamer and the target includes structure compatibility, stacking of aromatic rings, electrostatic and Vander Waals interactions, hydrogen bonding, or a combination of all these effects (Borisov et al., 2008, Ligler et al., 2009, Dorst et al., 2010). Aptamers are a useful alternative to antibodies as sensing molecules, thus introducing a new era of affinity biosensing because of their unique character. Aptamers to target small organic and inorganic compounds such as proteins, peptides, amino acids, nucleotides, drugs, and heavy metal ions can be produced. The chemical synthesis is aptamers is easy and purification steps required are simple and cheap, which eliminates the batch-to-batch variation found when using antibodies. Furthermore, Stability, affinity, and specificity of the molecules are improved by modification of aptamers through chemical synthesis. In addition, aptamers are more stable, and more resistant to denaturation and degradation than antibodies (Mehta et al., 2012, Jo et al., 2011).

DNAzymes:-DNAzymes (catalytic DNAs or deoxyribozymes) are functional nucleic acids. These bind to specific targets by folding into a well defined three-dimensional structure. (Hollenstein et al., 2008, Li et al., 2009, Wang et al., 2013, Xiang et al., 2009) DNAzymes can generally be obtained through in vitro selection, allowing them to function in the presence of a specific target of choice. Allosteric DNAzymes or aptazymes are class of functional nucleic acids generated by combination of DNAzymes that can perform chemical modifications on nucleic acids, and aptamers that can bind with a broad range of molecules (Hollenstein et al., 2008). DNAzymes provide clear-cut recognition and exact quantification of environmental pollutants, ranging from low-molecularweight organic or inorganic substrates and macromolecules to metal ions through combination of nano-biological recognition probes and the sensitivity of laser-based optical detection (Li et al., 2009, Wang et al., 2013, Xiang et al., 2009).The extensive application of RNA-cleaving DNAzymes is because of their simple reaction conditions, fast turnover rates, and significant possible modifications of their substrate lengths (Xiang et al., 2009). The high selectivity of 
DNAzymes toward specific targets makes them ideal biorecognition molecules for biosensing. Numerous DNAzyme-based optical biosensors have been developed for the detection of various heavy metal ions, such as $\mathrm{Mg} 2+, \mathrm{Ca} 2+, \mathrm{Zn} 2+, \mathrm{Pb} 2+, \mathrm{Cu} 2+$, $\mathrm{Co} 2+, \mathrm{Mn} 2+, \mathrm{Hg} 2+$, and $\mathrm{Ag}+$ because of their facile operation, high sensitivity, and easily detectable signals (Hollenstein et al., 2008, Li et al., 2009, Wang et al., 2013, Xiang et al., 2009). Given the tremendous advances made in the areas of functional DNA and nanotechnology, DNAzymes and aptazymes have already been applied to almost every aspect of DNA nanotechnology, resulting in new materials and devices that may be employed in the environmental monitoring field (Hollenstein et al., 2008, Li et al., 2009, Wang et al., 2013, Xiang et al., 2009, Long et al., 2013).

Whole Cells: Whole cells are outstanding indicators of toxic compounds. The bioluminescent light production or fluorescence properties of large number of microbial-based optical biosensors have been used to detect toxicity and pollutants. Heavy metals and inorganic pollutants in wastewater were rapidly and effectively monitored using whole-cell bacterial biosensors developed by Olaniran et al., when Shigellasonnei and Escherichia coli, were used the biosensors were found to be receptive to the toxicity of wastewater effluents. With increase in concentration of heavy metals and inorganic pollutants in water bioluminescence increases with a correlation coefficient (r2) as high as 0.995 and 0.997 , respectively. Achieving rapid, sensitive and cost effective detection of wastewater quality is the capability of bacterial biosensors. For $\mathrm{pH}$ and oxygen an integrated fluorescence-based sensor, was reported by Arain et al., in which bacterial respiratory activity was monitored via the decrease in the oxygen partial pressure of the closed system and also via the decrease in $\mathrm{pH}$ value. The detection of inhibitory effect of toxic metal ions on the cellular activity of $\mathrm{E}$. coli and Pseudomonas putida was then achieved. Amaro et al., reported a whole-cell biosensor for the detection of heavy metals based on metallothionein promoters from Tetrahymena thermophila. Two gene constructs using the Tetrahymena thermophila MTT1 and MTT5 metallothionein promoters linked with the eukaryotic luciferase gene, regarded as a reporter. This kind of biosensor appears to be the most sensitive eukaryotic metal biosensor among other published cell biosensors. Using bioluminescent bacteria immobilized in an alginate matrix on the bottom of the wells in a 96-well microplate. Air toxicity is monitored using fiber-optic biosensor developed by; Eltzov et al., Bioluminescence was suppressed when the biosensor was exposed to toxic compounds present in air Chloroform could be detected by this method with a LOD of $6.6 \mathrm{ppb}$. The same group developed a flowthrough fiber-optic sensing system by immobilizing two other bacterial strains for the online monitoring of toxic pollutants in water (Eltzov et al., 2009, Amaro et al., 2011, Arain et al., 2006, Eltzov et al., 2011, Olaniran et al., 2011). The sensor could detect pollutants in flowing tap water and surface water within $24 \mathrm{~h}$, but a loss of functionality of the bacteria was observed after longer periods.

\section{Optical Biosensors}

Evanescent wave fiber-optic immunosensors (EWFI): Extensive range of pollutants, such as TNT, 2, 4-D, atrazine, E. coli O157:H7, and Staphylococcal enter toxin $\mathrm{B}$ have been detected using EWFI, which are swift, exact, receptive, money-making and appropriate for real-time on-site detection ( $\mathrm{Li}$ et al., 2009). Conventional EWFI is not a transportable device because it requires critical optical configuration and is costly 
because of having the large size with numerous optic components (e.g., chopper, off-axis parabolic reflector, and biconvex silica lens). Evanescent wave all-fiber biosensor (EWAB) based on a single-multifiber optic coupler which is simple, compact and portable was developed for simultaneous detection of 2, 4, -D and MC-LR. (Long et al., 2009). Significant signal enhancement was achieved by plummeting the optical components and configuration with the use of single-multi-fiber optic coupler, which enables both the transmission of the excitation light and the collection and transmission of fluorescence. Combination tapered fiber probes were produced by the tube-etching method and modified by covalent attachment of the MC-LR-OVA (recognition element) to a self-assembled monolayer formed onto the probe. This probe is highly resistive to nonspecific binding of proteins and can be reused more than 150 times with a LOD of $0.03 \mu \mathrm{g} / \mathrm{L}$ and a LOD of $0.07 \mu \mathrm{g} / \mathrm{L}$ for MC-LR and 2, 4$\mathrm{D}$, respectively (Long et al., 2008).

SPR Biosensors: When the surface of a thin metal film is excited by an incident light under total internal reflection conditions, it generates the evanescent electromagnetic field with which a surface-sensitive optical technique is associated called Surface Plasmon Resonance (SPR) (Cooper 2002). Due to the verity the evanescent field diminishes exponentially with escalating distance of penetration from the interface, the monitoring of only surface-confined molecular interactions occurring on the transducer surface is promoted by SPR. Most of the SPR instruments use a Kretchmann configuration working at attenuated total reflectance (ATR) for excitation of surface plasmons, which can detect a small refractive index change at the metal/analyte interface, and the information of the molecular interactions can be obtained by measuring the optical intensity (or phase/polarization) of light reflected from the optical instrument. Real-time detection of miniature changes in the refractive index is permitted by SPR biosensors through the fastening of biorecognition molecules (e.g., antibodies) immobilized on a transducer surface with their biospecific targets (e.g., analytes) in solution. SPR biosensors have been used extensively for applications including clinical diagnosis, drug discovery, food analysis, environmental monitoring, since their introduction in early 1990 (Shankaran et al., 2007). In general, a SPR biosensor is comprised of several important components: a light source, a detector, a transduction surface (e.g., gold-film), a prism, biorecognition molecule (e.g., antibody/antigen, DNA and aptamer) and a flow system. The use of SPR to detect environmental contaminants, including atrazine, Dichloro-DiphenylTrichloroethane (DDT), 2, 3, 7, 8tetrachlorodibenzo-p-dioxin, carbaryl, 2, 4-D, benzo[a]pyrene $(\mathrm{BaP})$, biphenyl derivatives, and trinitrotoluene (TNT), has recently gained considerable interest (Cooper 2002, Shankaran et al., 2007, Long et al., 2011, Long et al., 2010, Miura et al., 2003) An SPR immunosensor for $\mathrm{BaP}$, a carcinogenic endocrine disrupting chemical, was reported to have a LOD of $10 \mathrm{ppt}$ (Miura et al., 2003).In natural water samples for the analysis of carbaryl a portable SPR-based immunosensor was developed. (Mauriz et al., 2006) Based on a binding inhibition immunoassay format, this immunosensor has a LOD of $1.38 \mu \mathrm{g} / \mathrm{L}$. The sensor surface covalently modified by the analyte derivative allows the reuse for more than 220 regeneration cycles. The immunoassay performance of the biosensor was validated with respect to conventional highperformance liquid chromatography-mass spectrometry, and the correlation between methods was in good agreement $(\mathrm{r} 2>0.998)$ for real water samples. Kim et al., fabricated the sensing surface of the SPR immunosensor 
simply by covalent amide binding of 2, 4-DBSA conjugate on the Au-thiolate selfassembly. A LOD of $0.1 \mathrm{ppb} 2,4-\mathrm{D}$ is established with a response time of only 4 min. One of the advantages is that the immunoaffinity interactions of anti-2, 4-D antibody with the 2, 4-D-BSA sensor surface and 2, 4-D in solution could be significantly modulated by the control immobilization of 2 , 4-D-BSA on the SAM surface. As a result, the sensitivity of the SPR immunosensor is enhanced by about 10 -fold to $10 \mathrm{ppt}$ without using any high-molecular-weight labels. Localized surface Plasmon resonance (LSPR) effect using AuNP for signal amplification was also investigated (Kim et al., 2008, Kawaguchi et al., 2008). The amplification method of indirect competitive inhibition and LSPR were integrated for the fabrication of an immunosurface using AuNP. The detection range of TNT using this immunosurface was from $10 \mathrm{ppt}$ to $100 \mathrm{ppb}$.

Bioremediation: The term of bioremediation has been made of two parts: "bios" means life and refers to living organisms and "to remediate" that means to solve a problem. "Bioremediate" refers to the use biological organisms to solve an environmental problem such as contaminated soil or groundwater. Environmental pollutants are degraded or pollution is prevented by the use of living micro organisms through bioremediation. In other words, it is a technology for removing pollutants from the environment thus restoring the original natural surroundings and preventing further pollution (Sasikumar et al., 2003). Bioremediation enables utilization of diverse metabolic abilities of microorganisms to convert contaminants to risk-free products by mineralization, generation of carbon (IV) oxide and water, or by conversion into microbial biomass, so as to clean the contaminated environment (Baggot et al., 1993, Mentzer et al., 1996). Presence of metabolically capable microbial populations, suitable environmental growth conditions, and appropriate levels of nutrients and contaminants are important site factors required for successful bioremediation.

Pollution from air or from aquatic or terrestrial systems is also reduced using biological systems (EFB 1999), bioremediation also involves lessening of toxic components by extracting a microbe from the environment and exposing it to a target contaminant. (Vallero, 2010) Thus, the purpose of bioremediation is the employment of biosystems such as microbes, higher organisms like plants (phytoremediation) and animals to reduce the potential toxicity of chemical contaminants in the environment by degrading, transforming, and immobilizing these unwanted compounds.

Biodegradation is the use of living organisms to enzymatically and otherwise attack numerous organic chemicals and break them down to lesser toxic chemical species. Biotechnologists and bioengineers classify pollutants with respect to the ease of degradation and types of processes that are responsible for this degradation, sometimes referred to as treatability (Vallero, 2010).Most commonly occurring bioremediation option is the use of microorganisms for biodegradation. Microorganisms meet their growth and energy needs by break down of most compounds. These biodegradation processes may or may not need air. In some cases, the metabolic pathways normally used by organisms for growth and energy supply may also be used to break down pollutant molecules. In these cases, known as co metabolisms, the microorganism does not benefit directly. Researchers have taken advantage of this phenomenon and used it for bioremediation purposes (EFB 1999). Detoxification of pollutants by mineralizing pollutants to carbon dioxide $\left(\mathrm{CO}_{2}\right)$, water $\left(\mathrm{H}_{2} \mathrm{O}\right)$, and harmless inorganic salts is called the complete 
biodegradation (EFB 1999). Incomplete biodegradation (i.e., mineralization) will produce compounds that are usually simpler (e.g., cleared rings, removal of halogens), but with physical and chemical characteristics different from the parent compound. In addition, side reactions can produce compounds with varying levels of toxicity and mobility in the environment (Vallero, 2010). Biodegradation may occur spontaneously, in which case the expressions "intrinsic bioremediation" or "natural attenuation" is often used (EFB 19994). In many cases for natural attenuation to take place the natural circumstances may not be favorable due to inadequate nutrients, oxygen, or suitable bacteria. Supplying of one or more of the missing/inadequate environmental factors help in improving such situations. Extra nutrients (EFB 19994) were disseminated to speed up the breakdown of the oil spilled on 1000 miles of Alaskan shoreline by the super tanker Exxon Valdez in 1989.

According to Vallero, there are millions of indigenous species of microbes living at any given time within many soil environments. The bioengineer simply needs to create an environment where those microbes are able to use a particular compound as their energy source (Vallero, 2010). Biodegradation processes is not new, it had been observed empirically for centuries, but putting them to use as a distinct field of bioremediation began with the work of Raymond et al., It was studied that the addition of nutrients to soil increases the abundance of bacteria that was associated with a proportional degradation of hydrocarbons, and the hydrocarbons under consideration were petroleum by-products (Raymond et al., 1975). Bioremediation success depends on the following:(1)the growth and survival of microbial populations; and (2) the ability of these organisms to come into contact with the substances that need to be degraded into less toxic compounds;(3) sufficient numbers of microorganisms to make bioremediation successful;(4) the microbial environment must be habitable for the microbes to thrive.(Vallero, 2010). Sometimes, environment becomes toxic to microbial population due to elevated concentrations of compounds. Therefore, the bioengineer must either use a method other than bioremediation or modify the environment (e.g., dilution, change of $\mathrm{pH}$, pumped Oxygen, adding organic matter, etc.) to make it habitable. An imperative amendment is the elimination of nonaqueous-phase liquids (NAPLs) since the microbes' biofilm and other mechanisms usually work best when the microbe is attached to a particle; thus, most of the NAPLs need to be removed, by vapour extraction (Vallero, 2010). Liquids (water, solutes, and nutrients) are difficult to pump through low permeability soils, like clays and hence these systems are difficult to treat. Sandy soils allow mobility and greater likelihood of contact between the microbes and the contaminant, so bioremediation works best in these soils. Therefore, an understanding of the environmental conditions sets the stage for problem formulation (i.e., identification of the factors at work and the resulting threats to health and environmental quality) and risk management (i.e., what the various options available to address these factors are and how difficult it will be to overcome obstacles or to enhance those factors; that make remediation successful). In other words, bioremediation is a process of optimization by selecting options among a number of biological, chemical and physical factors these include correctly matching the degrading microbes to conditions, understanding and controlling the movement of the contaminant (microbial food) so as to come into contact with microbes, and characterizing the abiotic conditions controlling both of these factors. 
Optimization can vary among options, such as artificially adding microbial populations known to break down the compounds of concern. Only a few species can break down certain organic compounds (Vallero, 2010). Toxicity to the microbial population and inherent biodegradability of the compound are two major limiting factors of any biodegradation process.

\section{Bioremediation of heavy metal} contaminated soil and waste water using micro organisms:-Microorganisms play a significant and vital role in bioremediation of heavy metal contaminated soil and wastewater. Indigenous soil microbes appear well suited for $\mathrm{Cr}$ (VI) transformation in highly contaminated soil. Very stable final chromium forms can be achieved as a result of microbial activity, with minimal risk of rerelease of $\mathrm{Cr}$ (VI). In liquid treatment system, biotransformation of $\mathrm{Cr}$ (VI) by pure culture has been studied under a range of redox (aerobic and anaerobic), temperature (10$\left.45^{\circ} \mathrm{C}\right)$ and $\mathrm{pH}$ (6.5-9.5 conditions). Escherichia coli ATCC 33456 transformed Cr (VI) faster at $10^{\circ} \mathrm{C}$ to $45^{\circ} \mathrm{C}$ under anaerobic than at $10^{\circ} \mathrm{C}$ to $35^{\circ} \mathrm{C}$ unders aerobic condition. The phenomenon of bio-absorption and bioaccumulation of chromium in metal and chromium contaminated soil and water help in bioremediation using many genera of microbes like Bacillus, Enterobacter, Escherichia, Pseudomonas and also some yeasts and fungi. (Bader et al., 1999, Bopp et al., 1988, Cifuentes et al., 1996, Garbisu et al., 1998, Ishibashi et al., 1990, James et al., 1983, Kotas et al., 2000, Losi et al., 1994, Nies et al., 1999, Philip et al., 1998, Shen et al., 1994, Wang et al., 1989).The bioaccumulation of $\mathrm{Cr}$ (VI) and ability to remove heavy metal like $\mathrm{Cr}$ (VI) from tannery effluents by the heavy metal resistant fungi and bacteria isolated from the soil samples of tanning industries were found. The $\mathrm{pH}$ of the effluent was significant in removing the metal. The heavy metal removal by the bacteria Pseudomonas was attributed to the cellular growth of these organisms. The reactive intermediates and $\mathrm{Cr}$ (III) are formed through the biotransformation of Chromium (VI) by undergoing enzymatic reduction. (Seng et al., 2002). Toxic Cr (VI) from contaminated environment can be reduced using chromium resistant bacteria isolated from the soil. The mechanism of Cr-tolerance or resistance of selected microbes is of particular importance in both bioremediation and waste water treatment technology (Polisak et al., 2010). Algae such as Charophyte, Nitella pseudo flabellate is applicable in the remediation of $\mathrm{Cr}$ (VI) contaminated water at different calcifying potentials (Gomes et al., 2009). Hexavalent chromium can be reduced into its trivalent form by Bacillus species. These bacteria could reduce $91 \%$ of Chromium from the medium after 96 hours and was also capable of reducing $84 \%$ chromium from the industrial effluents in Lahore after 144 hours (Rehman et al., 2008). Morales et al., wanted to segregate and examine chromium-resistant microorganisms suitable for bioremediation. They found that Streptomyces $\mathrm{sp}$ was efficient at removing $\mathrm{Cr}$ (VI) by promoting reduction to $\mathrm{Cr}$ (III) and regardless of its negative effect on growth and development tolerated heavy metals and elevated levels of chromium. Hence chromium-resistant microorganisms are a promising candidate for detoxification of sites containing heavy metals (Morales et al., 2007). More data of chromium reduction was obtained by scientists from Pseudomonas aeruginosa (Ganguli et al., 2002), Bacillus sp (Camargo et al., 2003, Meghraj et al., 2003), Streptomyces (Amorosa et al., 2001), from Pseudomonas fluorescens (Appanna et al., 1996, Khan and Ahmad 2006), from yeasts like Pichiguilliermondii (Ksheminska et al., 2003) also from Micrococcus sp and Aspergillus sp in Tamil Nadu (Congeevaram 
et al., 2007]. Aspergillus niger biomass has been found to be very effective in bio absorption of $\mathrm{Cr}$ (III) and $\mathrm{Cr}$ (VI) in spent chrome liquor. For hazardous material degradation not only microorganism are involved, plants are also involved in breakdown of complex molecules and immobilize waste materials from soil/water this process is known as phytoremediation. It has been reported that in Arabidopsis thaliana (Flowering plant), arsenate reductase and gamma- glutamyl cysteine synthase are coded by two bacterial genes (arsC and gECS1) respectively, the over expression of these genes enables this plant to capture arsenate and degrade it (Hooker and Skeen 1999). It is postulated that; environmental security is contributed appreciably by transgenic plants (Frerot et al., 2006). Biotechnology somehow solves these problems and plays a significant role in environmental remediation by helping us to clean environmental pollution and maintain natural ecosystem.

Genetically engineered microorganisms in environmental remediation: A variety of organisms reside in the soil. They range from complex as insects to simple organisms like earth worms. They could be evident as former and could be indistinguishable, but performing a great role in maintenance and fertility of soil, like bacteria. Energy is not transported to the cells vital to run their metabolism proficiently during most of the enzymatic reactions involving substrate and is unintentional. So human made contaminants such as chlorobiphenyls which are present in the environment by somehow being a part of our metabolism (Bayat et al., 2015). These enzymes stay in study for decades because they have a very complex structure and contain many different substrates for their performance. So serious amendment is made in these enzymes by changing their respective genes in genome of different organisms mostly bacteria. The first enzymes considered having the potential of carrying out an angular dioxygenation, that is, oxygenation at a pair of adjoining carbon atoms, one of which is concerned in one of the bridges between the two benzene rings was dioxin dioxygenase of Sphingomonas sp. strain RW1. The preferred genes are now characterized and whereas genes coding for multi component dioxygenase are usually gathered, those coding for dioxin dioxygenase were unpredictably scattered throughout the chromosome (Sharma 2012). Another comparatively identification is made for lineage of ring activating dioxygenases has been modified genetically to contain, between the genes coding for the electron transport chain of a naphthalene dioxygenase, genes coding for subunits of an enzyme catalyzing a separate step in the pathway, that is, salicylate 5-hydroxylase. Even other unrelated naphthalene and phenanthrene systems from Rhodococcus sp. NCIMB 12038 and Burkholderia sp. strain RP007 have been described, but no substrate specificity profiles have been given. There are so many examples of using microorganisms for bioremediation. The organisms can easily be manipulated and by modifying their genome everything can be made from these organisms because their genome does not need so many regulators as eukaryotic genome require,

Phyto remediation: -Phytoremediation is defined as utilizing the natural abilities of plants to uptake, accumulate, and degrade constituents of contaminants in soil and water to clean up the environment. Phytoremediation is applicable to a wide variety of contaminants including plentiful metals and radio nuclides, different organic compounds (such as chlorinated solvents, BTEX, PCBs, PAHs, pesticides/insecticides, explosives, nutrients, and surfactants as is reported in results of various research and development. According to information reviewed, general site conditions best suited 
for potential use of phytoremediation include large areas of low to moderate surface soil (0 to 3 feet) contamination or large volumes of water with low-level contamination subject to low (stringent) treatment standards. Depth to groundwater for in situ treatment is limited to about 10 feet, but ex situ treatment in constructed troughs or wetlands has also been investigated (Brown 1995, Carricaburu and Lisa. 1996, Dushenkov et al., 1995, Schnoor et al., 1995).There are five basic types of phytoremediation techniques:-

1) Rhizofiltration, is a water remediation technique in which plant roots uptake the contaminants.

2) Phyto extraction, is a soil remediation technique involving uptake of contaminants from soil

3) Phytotransformation, is applicable to both soil and water, in which contaminants are degraded through plant metabolism

4) phyto-stimulation or plant-assisted bioremediation, also used for both soil and water, in which microbial biodegradation is stimulated through the activities of plants in the root zone, and

5) Phytostabilization, the mobility and migration potential of contaminants is reduced using in soil. (Brown. 1995, Carricaburu and Lisa. 1996).

Phytoremediation technologies are advantageous as compared to traditional remediation technologies, chief advantages include likelihood of generating less secondary wastes, minimal connected environmental disturbance, and the capability to leave soils in place and in an exploitable condition following treatment. In spite of advantages, it has certain disadvantages which include the extended lengths of time required (usually several growing seasons), depth limitations ( 3 feet for soil and 10 feet for groundwater), and the likelihood of contaminant entrance into the food chain through animal consumption of plant material.

\section{Types of phyto remediation}

Rhizofiltration: Rhizofiltration of surface water may be conducted in situ by growing plants directly in the contaminated water body, rhizofiltration of groundwater can also be done in situ if ground water is positioned within the Rhizosphere (root zone).Alternately, in rhizofiltration contaminated groundwater is pumped into troughs filled with the large root systems of appropriate plant species. Efficient absorption of metals from the contaminated groundwater into root tissues is permitted by the large surface areas of root systems. Metals from ground water are also detached through precipitation caused by exudates (liquids released from plant tissues) in addition to removal through absorption. When the groundwater passes through the plant troughs, the precipitates are filtered out and then treated water is removed from the process loop. Roots are harvested, and depending on the species of plant used, shoots may be transplanted to grow new roots. Plants can be replaced in the system to ensure constant operation results. Rhizofiltration using sunflowers has been used in the remediation of radio nuclides from surface water near Chernobyl (strontium and cesium) and in water using a rhizofiltration system, as described above, at a DOE facility in Ohio (Brown. 1995, Dushenkov et al., 1995, Salt et al., 1995, Vance 1996).

Phytotransformation: Phytotransformation can be accomplished for in-situ remediation of both surface and ground water, Surface water includes ponds or wetlands. 
Groundwater can be remediated Insitu if the water table is within the zone tapped by deeprooted plants such as poplars or ex situ by pumping water to troughs or constructed wetlands containing appropriate plants. In the Phytotransformation process, plants take up organic contaminants and degrade them to less toxic or non-toxic compounds (Brown. 1995, Schnoor et al., 1995, Vance. 1996, Black. 1996). This technique is being tested on explosives-contaminated groundwater (TNT and RDX) at Milan Army Ammunition Plant in Tennessee by the U. S. Army Corps of Engineers Waterways Experimental Station (WES) (Brown 1995, Schnoor et al., 1995, Salt et al., 1995, Black. 1996).

In addition, an Environmental Security Technology Certification Program (ESTCP) project is testing the ability of trees with roots tapping groundwater to degrade TCE and hydrazine present in the aquifer (ESTCP 1996). The U.S. Air Force is planning to evaluate phytoremediation through field studies followed by cell cultures and biochamber studies (Edwards and Robert 1996).

Plant-Assisted Bioremediation: This is used for conduction of near-surface bioremediation. Under this technique appropriate plants are installed in these areas. The plants provide carbonaceous material from liquids released from roots and through the decay of root tissue. Besides this oxygen content in the bioremediation area is increased due to release of oxygen from the root system of plants. The microbial activity increases due to additions from plant activity which results in increase in the contaminant degradation. The roots of plants have beneficial effects on rate of Insitu bioremediation by microorganisms was studied under ESTCP project (Carricaburu and Lisa. 1996, Schnoor et al., 1995, Vance. 1996, Black 1995, ESTCP 1996, Jordahl et al., 1997).

\section{Soil remediation methods}

Phytoextraction: In this process plant tissues help in removal of metals, radio nuclides, and certain organic compounds (i.e., petroleum hydrocarbons) by direct uptake. Hyper accumulators of one or more species of the concerned contaminants are planted for the implementation of phyto-extraction program. It has been determined from preliminary field testing, that certain amendments (i.e., fertilizer, water, etc.) may be required to ensure successful plant growth. Lengths of time before harvesting the plants are also determined from preliminary testing, and after this period of time, plant tissue is removed and, if necessary, a new crop of plants are planted. Although testing has focused on single plants, several species may be used at a site, either at the same time or subsequently, to remove more than one contaminant (Schnoor et al., 1995, Salt et al., 1995, Kumar et al., 1995, Newell and parry 1995).

Plants which have the ability to perform phytoextraction are characterized by (a) Ability to accumulate and tolerate high concentrations of metals in harvestable tissue. (2) Rapid growth rate. (3)High biomass production (This results in more metal removed per planting) (Salt et al., 1995, Black 1996, Kumar et al., 1995).

DOE field trials involving phytoextraction of metals and radio nuclides from soils are being conducted in association with Cornell University, at sites in Montana and Idaho (Brown 1995). Also, a study is being conducted by the University of Iowa and Kansas State University, in association with the Hazardous Substance Research Center (HSRC) at Kansas State, to determine the efficiency of poplars to take up and accumulate arsenic and cadmium in soils (Schnoor et al., 1995). 
Phytostabilization: Phytostabilization is the reduction in bioavailability of metals contaminants and reducing the potential for human exposure to these contaminants by the use of certain plant species through absorption and precipitation. In areas where natural vegetation is lacking due to high metals concentrations in surface soils or physical disturbances to surficial materials this technique is helpful for re-establishment of vegetation in these areas. The potential migration of contamination through wind erosion and transport of exposed surface soils and leaching of soil contamination to groundwater is decreased by metal tolerant species, so as to restore vegetation to these sites. (Erosion and leaching are common in unvegetated areas). Plants appropriate for Phytostabilization are tolerant to high levels of contaminants concentration, have the ability to immobilize the contaminants through uptake, precipitation, or reduction due to high root biomass production, have the tendency to retain contaminants in shoots rather than transferring to shoots, to avoid special handling and disposal of shoots. (Brown 1995, Schnoor et al., 1995, Black 1996, Munshower. 1996). Phytostabilization field studies are being conducted at the University of Iowa and Kansas State University, in conjunction with the HSRC at Kansas State. These tests involve the re vegetation of a mine tailings site in Kansas containing, elevated levels of cadmium, lead, and zinc, to reduce wind and water erosion (Banks et al., 1994).

Plant-Assisted Bioremediation: Plantassisted bioremediation techniques for soil remediation are same as groundwater application. This technique is being tested at a Chevron site in Ogden, Utah using alfalfa to address fuel contamination (Carricabura and Lisa. 1996) and at the University of Iowa using poplar trees to address atrazine contamination (Licht and Schnoor. 1996).
Some examples of genetically modified plants In recent years, hairy roots (HRs) have been productively used as research tools for selecting the abilities of different plant species to tolerate, accumulate, and/or remove environmental pollutants, such as TNT, PCBs, pharmaceutical, dyes from textile, phenolics, radionuclides, and heavy metals. The plants are associated with contaminants through their root system and have model system this makes plants more advantageous and beneficial. The hairy rooted plants use metabolic and catalytic pathways for uptake of pollutants, change their morphology and store them in different plant organs and conjugation. Plant roots entrap and degrade the pollutants by the liberation of chemicals such as peroxidases and laccases which act as enzymes. Biotechnology modifies the genome of plants in such a way that they can tolerate and disintegrate heavy non degradable pollutants. (Samanta et al., 2002). Agrobacterium-Ti plasmid transformation increase the chance of efficient embryo formation with a 1000-fold reasonable speed in Pinusabies. This happens by disarming the Agrobacterium tumifaciens strains and by modifying its vir genes. Embryonic Pinustaeda culture is able to get GUS expression 10 folds higher than normal. Cocultivation of $\mathrm{P}$. strobus embryogenic tissue with A. tumefaciens carrying a 35S-35SAMVgus: nptII fusion also resulted in the regeneration of efficiently transformed somatic embryos compounds produced by industrial waste (Poupin and Johnson 2005). Pinus, abies, Oak, scots pine has improved soil property by accumulating heavy metals.

\section{Phytoremediation of Heavy Metals}

Phytoremediation technology involves uptake of heavy metals in different amounts from the soil and storing them in harvestable parts of plant, it is a part of promising green technology (Chaturvedi et al., 2016). The 
changes in soil properties enable the plants to tolerate pollutants (Mench et al., 2009). Phytoremediation can be easily used for the treatment of soils containing heavy meals, and the biomass that is formed throughout the process can be further applied in biodiesel production. The plants suitable for this purpose have the capability to accumulate toxic heavy metals, these are called bio energy crops example Brassica species. Some plants can accumulate pollutants in tissues (Munir and Faisal 2016). Among the Energy crop that is used for the phytoremediation of soils contaminated by heavy metals, the most suitable for phyto- extraction is Jerusalem artichoke (Helianthus tuberosus L.). The highest heavy metal uptake was observed at a dose of $60 \mathrm{Mg}$ DMha-1 in the Jerusalem artichoke (Antonkiewicz et al., 2018). Hyper accumulating plants are fit to grow on soils contaminated with heavy metals and can be used to eradicate pollutants (Da Conceicao Gomes et al., 2016). Plants that contain greater than $10,000 \mathrm{mg} / \mathrm{kg}$ dry weight of $\mathrm{Zn}$ or Mn or more than $1000 \mathrm{mg} / \mathrm{kg}$ dry weight of $\mathrm{Ni}, \mathrm{Cu}$, or $\mathrm{Pb}$ or greater than $100 \mathrm{mg} / \mathrm{kg}$ dry weight of $\mathrm{Cd}$ in contaminated areas is considered as hyper accumulating plants. Important plants of families such as Lamiaceae, Fabaceae, Scrophulariaceae, Asteraceae, Euphorbiaceae, and Brassicaceae, are known to hyper accumulate toxic heavy metal are frequently used in the phytoremediation processes. Other than that, there have been reports of heavy metal hyper accumulation in about 500 plant species (Jaffre et al., 2013). Plants with greater hyper accumulating abilities include Alyssum bertolonii, Thlaspicaerulescens, Calendula officinalis, and Tageteserecta (Glick 2012). Higher concentrations of $\mathrm{Ni}, \mathrm{Zn}$, and $\mathrm{Cd}$ are best gathered by Thlaspicaerulescens (Assuncao et al., 2003). This plant can accumulate 500-52, $000 \mathrm{mg} \mathrm{kg}-1$ of $\mathrm{Zn}$ and $0.3-1020 \mathrm{mg} \mathrm{kg}-1$ of $\mathrm{Cd}$. Trees took more time in accumulating metals, even in low quantities still they are more suitable for phytoremediation because of their greater root system and biomass. This issue could be solved by using fast-growing plants instead of trees (Da Conceicao Gomes et al., 2016, He et $a l ., 2010)$. For example, the Poplusalba is a deciduous tree, which can accumulate zinc (Zn) in different plant parts such as leaves, stems, and roots. An increasing trend of $\mathrm{Zn}$ accumulation was observed in the leaves of Poplusalba with the application of SDS (Pierattini et al., 2010). The ability of the plants to assemble amplified levels of toxic metals within their tissues influences the phytoremediation process (Ma et al., 2016). The enzymes from some plants can break down a number of organic compounds but cannot degrade inorganic pollutants. Thus, there is a need to ensure that inorganic pollutants are less available in soils or extracted and accumulated in different parts of the plants and also reduce volatile versions of inorganic pollutants (Ribierodesouza 2012). Energy recovery strategies can be used to produce bioenergy from plant biomass, such as to form biodiesel. Fuel gas, char, and biooil can be produced via Pyrolysis, during which the biomass undergoes thermal degradation without oxygen (Lievens et al., 2013). Soils greatly polluted with toxic heavy metals can be remediated easily by growing plants that are tolerant to more than one heavy metal, can produce a good amount of harvestable biomass with enhanced growth rates, and are highly competitive (Jeffre et al., 2013).

\section{References}

Agraeber, K., Nakabayashi, K., Miatton, E., Metzger, G. L. and Soppe, W. J. 2012. Molecular mechanisms of seed dormancy. Plant Cell Environment. 35(10): 17691786.

Khalilian, M., Zolfaghari, M.R., Soleimani, M. 2015. High potential application in bioremediation of Selenate by Proteus 
hauseri strain QW4. Iranian Journal of Microbiology. 7: 94-102.

Chen, W., Mulchandani, A., Deshusses, M.A. 2005. Environmental biotechnology: challenges and opportunities for chemical engineers. AIChE Journal. 51: 690-695.

Bharagava, R.N., Saxena, G., Mulla, S.I. 2020. Introduction to industrial wastes containing organic and inorganic pollutants and bioremediation approaches for environmental management. Bioremediation of Industrial Waste for Environmental Safety. 1-18.

EFB, Environmental Biotechnology. European Federation of Biotechnology. Task group on public perceptions of Biotechnology Briefingpaper4, 2nd Edition, 1999, http:// www. kluyver. stm. Tudelft.nl/ efb/ home.htm.

Thevenot, D.R., Toth, K., Durst, R.A., Wilson, G.S. 2001. Electrochemical biosensors: Recommended definitions and classification. Biosens. Bioelectron. 16: 121-131.

Borisov, S.M., Wolfbeis, O. S. 2008. Optical biosensors. Chem. Rev. 108: 423-461

Shankaran, D.R., Gobi, K.V., Miura, N. 2007. Recent advancements in surface Plasmon resonance immunosensors for detection of small molecules of biomedical: food and environmental interest. Sens. Actuators B. 121: $158-177$

Justino, C.I.L., Freitas, A.C., Pereira, R., Duarte, A.D.C., 2015. Recent developments in recognition elements for chemical sensors and biosensors. Trends Anal. Chem. 68: 2-17.

Ispas, C.R., Crivat, G and Andreescu, S. 2012. Review: Recent developments in enzymebased biosensors for biomedical analysis. Anal.Chem. 45:168-186.

Luckham, R.E and Brennan, J.D.2010. Bioactive paper dipstick sensors for acetyl- cholinesterase inhibitors based on sol-gel/enzyme/gold nano-particle composites. Analyst. 135: 2028-2035.

Ligler, F.S. 2009. Perspective on optical biosensors and integrated sensor systems. Anal. Chem. 81: 519-526.
Malitest, C and Guascito, M.R. 2005.Heavy metal determination by biosensors based on enzyme immobilised by electropolymerisation. Biosens. Bioelectron. 20: 1643-1647.

Zhongn, Z., Fritzsche, M., Pieper, S.B., Wood, T.K., Lear, K.L and Dandy, D.S. 2011. Fiber optic mono oxygenase biosensor for toluene concentration measurement in aqueous samples. Biosens. Bioelectron. 26: 2407-2412.

Dorst, B.V., Mehta, J., Bekaertb, K., RouahMartin, E., Coen, W.D and Dubruelc, P. 2010. Recent advances in recognition elements of food and environmental biosensors: A review. Biosen. Bioelectron. 26: $1178-1194$.

Sheng, J.W., He, M.and Shi, H.C. 2007. A highly specific immunoassay for microcystin-LR detection based on a monoclonal antibody. Analytica Chimicaacta. 603: 111-118.

Ellington, A.D and Szostak, J.W. 1990. In vitro selection of RNA molecules that bind specific ligands. Nature. 346: 818-822.

Tuerk, C and Gold, L. 1990. Systematic evolution of ligands by exponential enrichment: RNA ligands to bacteriophage T4 DNA polymerase. Science. 249: 505-510.

Mehta, J., Rouah-Martin, E., Dorst, B.V., Maes, B., Herrebout, W and Scippo, M.L. 2012. Selection and characterization of PCBbinding DNA aptamers. Anal. Chem. 84: 1669-1676.

Jo, M., Ahn, J.Y., Lee, J., Lee, S., Hong, S.W., Yoo, J.W. 2011. Development of singlestranded DNA aptamers for specific bisphenol a detection. Oligonuleotides. 21: 85-91.

Hollenstein, M., Hipolito, C., Lam, C., Dietrich, D and Perrin, D.M. 2008. A highly selective DNAzyme sensor for mercuric ions. Angew. Chem. Int. 47: 4346-4350.

Li, T., Wang, E. and Dong, S. 2009. Potassiumlead-switched G-Quadruplexes: A new class of DNA logic gates. J. Am. Chem. Soc. 131: 15082-15083.

Wang, X.D and Wolfbeis, O.S. 2013.Fiber- 
optic chemical sensors and biosensors. Anal Chem. $\quad$ 85: 487-508.

Xiang, Y., Tong, A and Lu, Y.2009. A basic site-containing DNAzymes and aptamer for label-free fluorescent detection of $\mathrm{Pb}^{2+}$ and adenosine with high sensitivity, selectivity, and tunable Dynamic range. $J$. Am. Chem. Soc. 131: 15352-15357.

Long, F., Zhu, A., Gu, C and Shi, H. 2013. Recent Progress in Optical Biosensors for Environmental Applications. In :State of the Art in Biosensors: Environmental and Medical Applications; Rinken, T., Ed.; InTech: Rijeka, Croatia. 1: 4-28

Eltzov, E., Marks, R.S., Voost, S., Wullings, B.A and Heringa, M.B. 2009. Flowthrough real time bacterial biosensor for toxic compounds in water. Sens. Actuators B.142:11-18.

Amaro, F., Turkewitz, A.P., Martín-González, A and Gutiérrez, J.C. 2011. Whole-cell biosensors for detection of heavy metal ions in environmental samples based on metallothionein promoters from Tetrahymena thermophila. Microb. Biotechnol. 4: 513-522.

Arain, S., John, G.T., Kranse, C., Gerlach, J., Wolfbeis, O.S and Klimant, I. 2006 Characterization of microtiterplates with integrated optical sensors for oxygen and $\mathrm{pH}, \quad$ and their applications to enzyme activity screening, respirometry, and toxicological assays. Sens. Actuators B. 113:639-648.

Eltzov, E., Pavluchkov, V., Burstin, $\mathrm{M}$ and Marks, R.S. 2011. Creation of a fiber optic based biosensor for air toxicity monitoring. Sens. Actuators B. 155:859867.

Olaniran, A.O., Hiralal, L and Pillay, B. 2011. Whole-cell bacterial biosensors for rapid and effective monitoring of heavy metals and inorganic pollutants in wastewater. J. Environ. Monit. 13: 2914 2920.

Long, F., He, M., Zhu, A.N and Shi, H.C.2009. Portable optical immunosensor for highly sensitive detection of microcystin-LR in water samples. Biosens. Bioelectron. 24:
2346-2351.

Long, F., Shi, H.C., He, M. and Zhu, A.N. 2008. Sensitive and rapid detection of 2 , 4-dicholoro phenoxyacetic acid in water samples by using evanescent wave allfiber immunosensor. Biosens. Bioelectron.23: 1361-1366.

Cooper, M.A. 2002. Optical biosensors in drug discovery. Nat Rev Drug Discov. 1: 515528.

Shankaran, D.R., Gobi, K.V and Miura, N. 2007 Recent advancements in surface plasmonresonance immunosensors for detection of small molecules of biomedical, food and environmental interest. Sens. Actuators B. 121:158-177.

Long, F., Gao, C., Shi, H.C., He, M., Zhu, A.N and Klibanov, A.M. 2011. Reusable evanescent wave DNA biosensor for rapid, highly sensitive, and selective detection of mercury ions. Biosens. Bioelectron. 26: 4018-4023.

Long, F., He, M., Zhu, A., Song, B., Sheng, J and Shi, H. 2010 Compact quantitative optic fiberbased immunoarray biosensor for rapid detection of small analytes. Biosens. Bioelectron. 26: 16-22.

Miura, N., Sasaki, M., Gobi, K.V., Kataoka, C and Shoyama, Y. 2003. Highly sensitive and selective surface plasmon resonance sensor for detection of sub-ppb levels of benzo[a]pyrene by indirect competitive immunoreaction method. Biosens. Bioelectron. 18: 953-959.

Mauriz, E., Calle, A., Abad, A., Montoya, A., Hildebrandt, A and Barcelo, D. 2006. Determination of carbaryl in natural water samples by a surface Plasmon resonance flow-through immuno sensor. Biosens. Bioelectron. 21: 2129-2136.

Kim, S.J., Gobi, K.V., Tanaka, H., Shoyama, Y and Miura, N.A. 2008. simple and versatile self-assembled monolayer based surface Plasmon resonance immunosensor for highly sensitive detection of 2, 4-D from natural water resources. Sens. Actuators B.130:281-289.

Kawaguchi, T., Shankaran, D.R., Kim, S.J., Matsumoto, K., Toko, K and Miura, 
N.2008. Surface plasmon resonance immunosensor using $\mathrm{Au}$ nanoparticle for detection of TNT. Sens. Actuators B. 133: 467-472.

Sasikumar, C.S and Papinazath, T. 2003. Environmental bioremediation of polluted environment. In: Bunch MJ, Suresh VM, Kumaran TV. Editors. Proceedings of the third international conference on environment and health, Chennai, India, Dec 15-17, 2003. Department of Geography, University of Madras and Faculty ofEnvironmental Studies, York University: Chennai. p. 465-469.

Baggott, J. 1993 Biodegradable lubricants. A paper presented at the Institute of Petroleum Symposium: "Life cycle analysis and eco-assessment in the oil industry, "Nov. 1992. Shell, Englands

Mentzer, E and Ebere D. 1996. Remediation of hydrocarbon contaminated sites. A paper presented at 8 th biennial international seminar on the petroleum industry and the Nigerian environment, November, Port Harcourt.

Vallero, A.D. 2010. Environmental Biotechnology: A Biosystems Approach, Elsevier Academic Press, Burlington, Mass, USA, 1st edition,

Raymond, R.L., Jamisen, V.W and Hudson, J.O.1975 "Final Report on Beneficial simulation of Bacterial activity in groundwater containing petroleum products, " American Petroleum Institute, Washington, DC, USA.

Bader, J.L., Gonzalez, G., Goodell, P., Ali, A.M and Pillai, S.1999. Aerobic reduction of hexavalent chromium in soil by indigenous microorganism. Biorem $J$. 3:201-212.

Bopp, L.H. Ehrlich and H.L. 1988. Chromate resistance and reduction in Pseudomonas fluorescens strain LB300. Arch.Microbiol. 150:426-431.

Cifuentes, F.R., Lindemann, W.C and Barton, L.L.1996. Chromium sorption and reduction in soil with implications to bioremediation. Soil Sci. 161:233-241.
Garbisu, C., Alkorta, I., Llama, M.J and Serra, J.L.1998 Aerobic chromate reduction by Bacillus subtilis. Biodegradation.9:133141.

Ishibashi, Y., Cervantes, $\mathrm{C}$ and Silver, S. 1990.Chromium reduction in Pseudomonas putida. Appl Environ. Microbiol. 56: 2268-2270.

James, B.R and Barlett, R.J. 1983. Behaviour of chromium in soils: VII. Adsorption and reduction of hexalent forms. $J$ Environ Qual. 12:177-181.

Kotas, J and Stasicka, Z. 2000 Chromium occurrence in the environment and methods of its speciation. Environ Pollut.107:263-283.

Losi, M.E., Amrhein, C and Frankenberger, W.T. 1994. Bioremediation of chromatecontaminated groundwater by reduction and precipitation in surface soils. $J$ Environ Qual. 23: 1141-1150.

Nies, D.H. 1999. Microbial heavy-metal resistance. ApplMicrobiolBiotechnol. 51:730-750.

Philip, L., Iyengar, L and Venkobachar. 1998. $\mathrm{Cr}$ (VI) reduction by Bacillus coagulans isolated from contaminated soils. $J$ Environ Eng.124: 1165-1170.

Shen, H and Wang.1994. Biological reduction of chromium by E.coli. $J$ Environ Eng.120:560-572.

Wang, P.C., Mori, T., Komori, K., Sasatsu, M., Toda, K and Ohtake, H.1989. Isolation and characterization of an Enterobacter cloacae strain that reduces hexavalent chromium under aerobic conditions. Appl Environ Microbiol. 55: 1665-1669.

Seng, J.k and Bielefeldt, A.R.2002. Low temperature chromium (VI) biotransformation in soil with varying electron acceptor. $J$ Environ Qual. 31:1831-1841.

Polisak, B., Pocsi, I., Raspor, P and Pesti, M.2010. Interference of chromium with biological systems in yeasts and fungi: A review. $J$ Basic Microbiology.50:21-36.

Gomes, P.L and Asaeda, T. 2008. Phycoremediation of Chromium (VI) by 
Nitella and impact of calcium encrustation. J Hazad Mater. 166: 13321338.

Rehman, A., Zahoor, A., Muneer, B and Hasnain, S.2008. Chromium tolerance and reduction potential a Bacillus $\mathrm{sp.ev}_{3}$ isolated from metal contaminated wastewater. Bull Environ ContamToxicol. 81:25-29.

Morales, D.K., Ocampo, W and Zambrano, M.M.2007. Efficient removal of hexavalent chromium by a tolerant Streptomyces sp. Affected by the toxic effect of metal exposure. J ApplMicrobiol. 103:2704-2712.

Ganguli, and Tripathi A.K.2002. Bioremediation of toxic chromium from electroplating effluent by chromatereducing Pseudomonas aeruginosa $\mathrm{A} 2 \mathrm{Chr}$ in two bioreactors. ApplMicrobiolBiotechnol. 58:416-420.

Camargo, F.A., Okeke, B.C, Bento, F.M and Frankenberger, W.T. Invitro reduction of hexavalent chromium by a cell-free extract of Bacillus sp.ES 29 stimulated by $\mathrm{Cu}^{2+}$. ApplMicrobiolBiotechnol 2003; 62:569-573.

Meghraj, M., Avudainavagam, S and Naidu, R.2003. Toxiciy of hexavalent chromium and its reduction by bacteria isolated from soil contaminated with tannery waste. CurrMicrobiol 47:51-54.

Amoroso, M.J., Castro, G.R., Duran, A., Peraud, O., Oliver, G and Hill, Rt.2001. Chromium accumulation by two Steptomyces spp. Isolated from riverine sediments. $J$ IndMicrobiolBiotechnol. 26:10-215.

Appanna, V.D., Gazso, L.G., Huang, J and St Pierre, M.1996. Mechanism of chromium detoxification in Pseudomonas

fluorescens is dependent on iron. Bull Environ ContamToxicol. 57:875-880.

Khan, M.W.A and Ahmad, M. 2006. Detoxification and bioremediation potential of a Pseudomonas fluorescens isolate against the major Indian water pollutants. J Environ Sci Health A ToxHazard Subst Environ Eng. 41:659-
674.

Ksheminska, H., Jaglarz, A., Fedorovvch, D., Babyak, L., Yanovych, D and Kaaszycki, P.2003. Bioremediation of chromium by the yeast Pichia guilliermondii: toxicity and accumulation of $\mathrm{Cr}$ (III) and $\mathrm{Cr}$ (VI) and the influence of riboflavin on $\mathrm{Cr}$ tolerance. Micrbiol Res.158:59-67.

Congeevaram, S., Dharani, S., Park, J., Dexillin, $\mathrm{M}$ and Thamaraiselvi, K.2007. Bioabsorption of chromium and nickel by heavy metal resistant fungal and bacterial isolates. J hazard Mater.146:270-277.

Hooker, B.S and Skeen, R.S.1999. Transgenic phytoremediation blasts onto the scene. Nature Biotechnology.17: 428.

Frerot, H., Lefebvre, C., Gruber, W., Collin, C., Santos, A.D and Escarre, J.2006. Specific interactions between local metallicolous plants improve the phytostabilization of mine soils. Plant and Soil.282: 53-65.

Bayat, Z., Hassanshahian, M and Cappello, S. Immobilization of microbes for bioremediation of crude oil polluted environments: a mini review. The Open Microbiology Journal. 9: 48-54.

Sharma, S. 2012. "Bioremediation: features, strategies and applications". Asian Journal of Pharmacy and Life Science. 2: 202-213.

Brown, K.S.1995. The Green Clean: The Emerging Field of Phytoremediation Takes Root. Bio Science. 45: 579-582.

Carricaburu and Lisa. 1996, "Green Machine Helps Clean up Chemical Site," The Salt Lake Tribune, April 21, available at http://www.sltrib.com/96/APR/21/tbz/205 10332.HTM

Dushenkov, V., Kumar, P.B.A.N., Motto, H and Raskin, I. 1995."Rhizofiltration: The Use of Plants to Remove Heavy Metals from Aqueous Stream. Environmental Science and Technology. American Chemical Society. 29: 1239-1245.

Schnoor, J.L., Licht, L.A., Mccutcheon, S.C., Wolfe, N.L andCarreira, L.H.1995. Phytoremediation of Organic and Nutrient Contaminants. Environmental Science and Technology. 29: 318A-23A. 
Salt, D.E., Blaylock, M., Kumar, N.P.B.A., Dushenkov, V., Ensley, B.D and Chet, I.1995. Phytoremediation: A Novel Strategy for the Removal of Toxic Metals from the Environment Using Plants. Bio/ Technology. 13: 468-474.

Vance, D. 1996. Phytoremediation: Enhancing Natural Attenuation Processes, "The National Environmental Journal. 6: 3031.

Black, H. 1996. Absorbing Possibilities: Phytoremediation, " Innovations, Vol. 103, No. 12, December, Environmental Health Perspectives, National Institute for EnvironmentalHealth Sciences, available at http://www. Ephnet 1. neihs. nih. gov. docs/ 1995 /103 (12)/innovations. Html.

ESTCP FY95 Projects, "Plant Enhanced Bioremediation of Contaminated Soil and Groundwater, " available at http://www.acq.osd.mil/ens/ESTCPProjSu m.html (9 May 1996).

Edwards and Robert, 1996, personal communication, August 13, Booz, Allen \& Hamilton, San Antonio, TX.

Jordahl, J.L., Foster, L., Schnoor, J.L. Alvarez, P.J.1997. Effect of Poplar Trees (Populus spp.) on Microbial Populations Important to Hazardous Waste Bioremediation. Environ Toxicol Chem. 16:1318-1321.

Kumar, P.B.A.N., Dushenkov, V., Motto, H and Raskin, I.1995. Phytoextraction: The Use of Plants to Remove Heavy Metals from Soils. Environmental Science and Technology, American Chemical Society. 29:1232-1238.

Newell, J and Parry, J. 1995 "Innovation Across the Ocean: British Research Seeks Remedial Solutions, " Soil and Groundwater Cleanup Magazine, available at http:// www.gvi.net/soils/May.1995/brit.htm (9 May 1996).

Munshower, F.F.1996. "Acid Producing metalliferous Waste Reclamation by Material Reprocessing and Vegetative Stabilization'”, Project Description, Great Plains/Rocky Mountains Hazardous
Waste Research Center, Kansas State University, available at http://www.engg.ksu.edu/ HSRC/Annual.Research.html\#92-05 (9 May 1996)

Banks, M.K., Hetrick, B.A and Schwab, A.P. 1994. Impact of Soil Microflora on Revegetation Efforts in Southeast Kansas. The Great Plains/Rocky Mountains Hazardous Substance Research Center, Kansas State University, Manhattan, Kansas.

Licht, L.A and Schnoor, J.L. "Riparian Tree Buffer Impact on Non-point Source Surface Water Contamination: A Paired Agricultural Watershed Study, " Project Description, Great Plains/Rocky Mountains Hazardous Waste Research Center, Kansas State University, available at http://www.engg.ksu.edu/HSRC/Annual. Research.html\#92-05 (9 May 1996)

Samanta, S.K., Singh, O.V and Jain, R.K.2002. Polycyclic aromatic hydrocarbons: environmental pollution and bioremediation. Trends Biotechnol. 20: 243-248.

Poupin, M.J and Johnson, P.A.2005. Transgenic trees for a new era. In Vitro Cellular and Developmental Biology-Plant. 41: 91-101. Chaturvedi, R., Varun, M and Paul, M.S. 2016. Phytoremediation: Uptake and role of metal transporters in some members of Brassicaceae. In: Ansari AA, Gill SS, Gill R, Lanza GR, Newman L, editors. Phytoremediation: management of environmental Contaminants, International Publishing: Cham, Switzerland: Springer: 453-468.

Mench, M., Schwitzguebel, J.P., Schroeder, P., Bert, V., Gawronski, S and Gupta, S.2009. Assessment of successful experiments and limitations of phyto technologies: Contaminant uptake, detoxification and sequestration, and consequences for food safety. Environ. Sci. Pollut. Res int.16: 876-900.

Munir, I. and Faisal, M. 2016. Plant growthpromoting bacteria: A good source for 
phytoremediation of metal-contaminated soil. In Phytoremediation: Cham, Switzerland: Springer. 119- 129.

Antonkiewicz, J., Kolodziej, B., Bielinska, E.J., Witkowicz, R and Tabor, S.2018. Using Jerusalem Artichoke to Extract Heavy Metals from Municipal Sewage Sludge Amended Soil. Pol. J. Environ. Stud.27: 513-527.

Da Conceicao Gomes, M.A., Hauser-Davis, R.A., de Souza, A.N and Vitoria, A.P.2016. Metal phytoremediation: General strategies, genetically modified plants and applications in metal nanoparticle contamination. Ecotoxicol. Environ. Saf. 134:133-147.

Jaffre, T., Pillon, Y., Thomine, S and Merlot, S. 2013. The metal hyperaccumulators from New Caledonia can broaden our understanding of nickel accumulation in plants. Front. Plant Sci. 4: 279.

Glick, B.R.2012. Plant Growth-promoting Bacteria: Mechanisms and Applications. Scientifica.

Assuncao, A., Schat, $\mathrm{H}$ and Aarts, $M$. 2003.Thlaspi caerulescens, an attractive model species to study heavy metal hyperaccumulation in plants. New Phytol. 159: 351-360.
He, C.Q., Tan, G.E., Liang, X., Du, W., Chen, Y.L and Zhi, Y.G. 2010. Effect of Zntolerant bacterial strains on growth and $\mathrm{Zn}$ accumulation in Orychophragmus violaceus. Appl. Soil. Ecol.44:1-5.

Pierattini, E.C., Francini, A., Raffaelli, A and Sebastiani, L.2018. Surfactant and heavy metal interaction in poplar: A focus on SDS and Zn uptake. Tree Physiol.38: 109-118.

Ma, Y., Rajkumar, M., Zhang, C and Freitas, H. 2016. Beneficial role of bacterial endophytes in heavy metal phytoremediation. J. Environ. Manag. 174:14-25.

RibierodeSouza, S.C., Andrade, S.A.L., Souza, L.A and Schiavinato, M.A. 2012. Lead tolerance and phytoremediation potential of Brazilian leguminous tree species at the seedling stage. J Environ. Manag. 110: 299-307.

Lievens, C., Yperman, J., Vangronsveld, J and Carleer, R.2013. The metal hyperaccumulators from New Caledonia can broaden our understanding of nickel accumulation in plants. Front. Plant Sci. 4: 279.

\section{How to cite this article:}

Haleema Bano, Shayesta Islam, Faisal Noor and Ashraf Bhat, M. 2020. Biosensors and Bioremediation as Biotechnological Tools for Environmental Monitoring and Protection. Int.J.Curr.Microbiol.App.Sci. 9(10): 3406-3425. doi: https://doi.org/10.20546/ijcmas.2020.910.394 